\title{
Performance and Age of the Fastest Female and Male 100-km Ultramarathoners Worldwide From 1960 to 2012
}

\author{
Cejka, Nadine ; Knechtle, Beat ; Rüst, Christoph A ; Rosemann, Thomas ; Lepers, Romuald
}

\begin{abstract}
The purpose of this cross-sectional study was to investigate the change in 100-km running performance and in the age of peak performance for 100-km ultramarathoners. Age and running speed of the annual fastest women and men in all 100-km ultramarathons held worldwide between 1960 and 2012 were analyzed in 148,017 finishes with 18,998 women and 129,019 men using single, multivariate, and nonlinear regressions. Running speed of the annual fastest men increased from 8.67 to $15.65 \mathrm{~km} \cdot \mathrm{h}$ and from 8.06 to $13.22 \mathrm{~km} \cdot \mathrm{h}$ for the annual fastest women. For the annual 10 fastest men, running speed increased from $10.23 \pm 1.22$ to $15.05 \pm 0.29 \mathrm{~km} \cdot \mathrm{h}$ $(\mathrm{p}<0.0001)$ and for the annual 10 fastest women from $7.18 \pm 1.54$ to $13.03 \pm 0.18 \mathrm{~km} \cdot \mathrm{h}(\mathrm{p}<0.0001)$. The sex difference decreased from 56.1 to $16.3 \%$ for the annual fastest finishers $(\mathrm{p}<0.0001$ ) and from $46.7 \pm 8.7 \%$ to 14.0 $\pm 1.2 \%$ for the annual 10 fastest finishers $(\mathrm{p}<0.0001)$. The age of the annual fastest men increased from 29 to 40 years $(p=0.025)$. For the annual fastest women, the age remained unchanged at $35.0 \pm 9.7$ years $(p=0.469)$. For the annual 10 fastest women and men, the age remained unchanged at $34.9 \pm 3.2(\mathrm{p}=0.902)$ and $34.5 \pm 2.5$ years $(\mathrm{p}$ $=0.064)$, respectively. To summarize, $100-\mathrm{km}$ ultramarathoners became faster, the sex difference in performance decreased but the age of the fastest finishers remained unchanged at $\sim 35$ years. For athletes and coaches to plan a career as $100-\mathrm{km}$ ultramarathoner, the age of the fastest female and male 100-km ultramarathoners remained unchanged at $\sim 35$ years between 1960 and 2012 although the runners improved their performance over time.
\end{abstract}

DOI: https://doi.org/10.1519/JSC.0000000000000370

Posted at the Zurich Open Repository and Archive, University of Zurich ZORA URL: https://doi.org/10.5167/uzh-111219

Journal Article

Published Version

Originally published at:

Cejka, Nadine; Knechtle, Beat; Rüst, Christoph A; Rosemann, Thomas; Lepers, Romuald (2015). Performance and Age of the Fastest Female and Male 100-km Ultramarathoners Worldwide From 1960 to 2012. Journal of Strength and Conditioning Research, 29(5):1180-1190.

DOI: https://doi.org/10.1519/JSC.0000000000000370 


\title{
Performance and Age of the Fastest Female and MALE 100-KM UltramaRATHONERS WORLDWIDE From 1960 To 2012
}

\author{
Nadine Cejka, ${ }^{1}$ Beat Knechtle, ${ }^{2}$ Christoph A. Rüst, ${ }^{1}$ Thomas Rosemann, ${ }^{1}$ and \\ ROMUALD LEPERS ${ }^{3}$ \\ ${ }^{1}$ Institute of General Practice and for Health Services Research, University of Zurich, Zurich, Szwitzerland; \\ ${ }^{2}$ Gesundheitszentrum St. Gallen, St. Gallen, Szwitzerland; and ${ }^{3}$ INSERM U1093, Faculty of Sport Sciences, University of \\ Burgundy, Dijon, France
}

\begin{abstract}
Cejka, N, Knechtle, B, Rüst, CA, Rosemann, T, and Lepers, R. Performance and age of the fastest female and male 100-km ultramarathoners worldwide from 1960 to 2012. J Strength Cond Res 29(5): 1180-1190, 2015-The purpose of this cross-sectional study was to investigate the change in 100$\mathrm{km}$ running performance and in the age of peak performance for 100-km ultramarathoners. Age and running speed of the annual fastest women and men in all 100-km ultramarathons held worldwide between 1960 and 2012 were analyzed in 148,017 finishes with 18,998 women and 129,019 men using single, multivariate, and nonlinear regressions. Running speed of the annual fastest men increased from 8.67 to 15.65 $\mathrm{km} \cdot \mathrm{h}^{-1}$ and from 8.06 to $13.22 \mathrm{~km} \cdot \mathrm{h}^{-1}$ for the annual fastest women. For the annual 10 fastest men, running speed increased from $10.23 \pm 1.22$ to $15.05 \pm 0.29 \mathrm{~km} \cdot \mathrm{h}^{-1}$ ( $p<$ $0.0001)$ and for the annual 10 fastest women from $7.18 \pm$ 1.54 to $13.03 \pm 0.18 \mathrm{~km} \cdot \mathrm{h}^{-1}(p<0.0001)$. The sex difference decreased from 56.1 to $16.3 \%$ for the annual fastest finishers $(p<0.0001)$ and from $46.7 \pm 8.7 \%$ to $14.0 \pm$ $1.2 \%$ for the annual 10 fastest finishers $(p<0.0001)$. The age of the annual fastest men increased from 29 to 40 years $(p=0.025)$. For the annual fastest women, the age remained unchanged at $35.0 \pm 9.7$ years $(p=0.469)$. For the annual 10 fastest women and men, the age remained unchanged at $34.9 \pm 3.2(p=0.902)$ and $34.5 \pm 2.5$ years $(p=0.064)$, respectively. To summarize, $100-\mathrm{km}$ ultramarathoners became faster, the sex difference in performance decreased but the age of the fastest finishers remained unchanged at $\sim 35$ years. For athletes and coaches to plan a career as $100-\mathrm{km}$ ultramarathoner, the age of the fastest female and male $100-\mathrm{km}$
\end{abstract}

Address correspondence to Dr. Beat Knechtle, beat.knechtle@hispeed.ch. 29(5)/1180-1190

Journal of Strength and Conditioning Research

(C) 2015 National Strength and Conditioning Association

1180

Journal of Strength and Conditioning Research ultramarathoners remained unchanged at $\sim 35$ years between 1960 and 2012 although the runners improved their performance over time.

KEY WoRDS running, master athletes, sex difference, ultraendurance performance

\section{INTRODUCTION}

I

$\mathrm{n}$ the last years, there has been an increased interest in analyzing factors affecting performance in endurance and ultra-endurance running such as physiological characteristics $(35,40,46,49)$, psychological aspects $(17,20,34)$, anthropometric $(28,29)$ and training characteristics $(29,32)$, previous experience $(28,30)$, and the sex difference in performance $(1,11,26)$.

Further, several studies focused on analyzing the influence of aging on running performance for different running distances $(14,36,52)$. Age-related changes in endurance running performance have been reported to depend on sex (31), leisure or occupational physical activity (40), lifestyle (37), and disease (40).

Ultramarathon running races became increasingly popular in the past 20 years $(21,23,24)$. Over the past decades, the participation of master athletes-defined as athletes older than 35 years (43)-increased in ultramarathon races $(23,24,31)$. In a $100-\mathrm{km}$ ultramarathon such as the "100-km Lauf Biel" in Switzerland, the age group with the largest participation was the age group 40-49 years for both women and men (31). It has been shown that these middle-aged ultramarathoners were mainly married men, well educated, and maintained a healthy lifestyle (22).

The population in both developed and developing countries is aging, consequently the number of master athletes is expected to proceed with the increase as well $(41,52)$. The demography of age structure has changed in recent years and is predicted to continue over the next 50 years. The number of older adults is on the rise because of the considerable increase in longevity and decreasing fertility worldwide (41). 
TABLE 1. Comparison of linear and nonlinear regression analyses of running speed, sex difference, and performance density across years to determine which model is the best.*

\begin{tabular}{|c|c|c|c|c|c|c|c|c|c|}
\hline & $\begin{array}{l}\text { Kind of } \\
\text { regression }\end{array}$ & $\begin{array}{l}\text { Sum of } \\
\text { squares }\end{array}$ & DOF & $\mathrm{AIC}$ & $\begin{array}{l}\text { Best } \\
\text { regression } \\
\text { AlC-test }\end{array}$ & $\begin{array}{c}\text { Best } \\
\text { regression } F- \\
\text { test }\end{array}$ & Delta & Probability & $\begin{array}{l}\text { Likelihood } \\
\text { (\%) }\end{array}$ \\
\hline \multicolumn{10}{|l|}{$\begin{array}{l}\text { Running speed } \\
\text { annual top }\end{array}$} \\
\hline Women & $\begin{array}{l}\text { Polynomial } \\
\text { Linear }\end{array}$ & $\begin{array}{l}14.8 \\
47.05\end{array}$ & $\begin{array}{l}37 \\
42\end{array}$ & $\begin{array}{r}-33.57 \\
5.04\end{array}$ & Polynomial & Linear & 38.62 & $4.10 \times 10^{-09}$ & 100 \\
\hline Men & $\begin{array}{l}\text { Polynomial } \\
\text { Linear }\end{array}$ & $\begin{array}{l}29.45 \\
85.81\end{array}$ & $\begin{array}{l}44 \\
47\end{array}$ & $\begin{array}{r}-16.02 \\
29.54\end{array}$ & Polynomial & Polynomial & 45.56 & $1.27 \times 10^{-09}$ & 100 \\
\hline \multicolumn{10}{|c|}{$\begin{array}{l}\text { Running speed } \\
\text { annual top } 10\end{array}$} \\
\hline Women & $\begin{array}{l}\text { Polynomial } \\
\text { Linear }\end{array}$ & $\begin{array}{r}9.57 \\
27.52\end{array}$ & $\begin{array}{l}32 \\
33\end{array}$ & $\begin{array}{c}-41.0 \\
-6.29\end{array}$ & Polynomial & Polynomial & 34.71 & $2.89 \times 10^{-09}$ & 100 \\
\hline Men & $\begin{array}{l}\text { Polynomial } \\
\text { Linear }\end{array}$ & $\begin{array}{r}3.08 \\
26.76\end{array}$ & $\begin{array}{l}39 \\
42\end{array}$ & $\begin{array}{r}-107.90 \\
-19.77\end{array}$ & Polynomial & Polynomial & 88.13 & $7.28 \times 10^{-20}$ & 100 \\
\hline \multicolumn{10}{|l|}{ Sex difference } \\
\hline Annual fastest & $\begin{array}{l}\text { Polynomial } \\
\text { Linear }\end{array}$ & $\begin{array}{r}728.25 \\
2,132.06\end{array}$ & $\begin{array}{l}41 \\
44\end{array}$ & $\begin{array}{l}136.02 \\
178.55\end{array}$ & Polynomial & Linear & 42.52 & $5.82 \times 10^{-09}$ & 100 \\
\hline $\begin{array}{l}\text { Annual } 10 \\
\text { fastest }\end{array}$ & $\begin{array}{l}\text { Polynomial } \\
\text { Linear }\end{array}$ & $\begin{array}{l}255.72 \\
738.96\end{array}$ & $\begin{array}{l}30 \\
34\end{array}$ & $\begin{array}{l}82.58 \\
110.9\end{array}$ & Polynomial & Linear & 28.31 & $2.89 \times 10^{-09}$ & 99.99 \\
\hline $\begin{array}{l}\text { Performance } \\
\text { density }\end{array}$ & & & & & & & & & \\
\hline Women & $\begin{array}{l}\text { Polynomial } \\
\text { Linear }\end{array}$ & $\begin{array}{r}515.8 \\
1,731.5\end{array}$ & $\begin{array}{l}31 \\
33\end{array}$ & $\begin{array}{l}100.9 \\
138.6\end{array}$ & Polynomial & Polynomial & 37.73 & $6.40 \times 10^{-09}$ & 100 \\
\hline Men & $\begin{array}{l}\text { Polynomial } \\
\text { Linear }\end{array}$ & $\begin{array}{l}364.0 \\
426.2\end{array}$ & $\begin{array}{l}30 \\
31\end{array}$ & $\begin{array}{l}83.6 \\
86.5\end{array}$ & Polynomial & Polynomial & 2.94 & 0.18 & 81.31 \\
\hline
\end{tabular}

${ }^{*} \mathrm{AIC}=$ Akaike's information criteria.

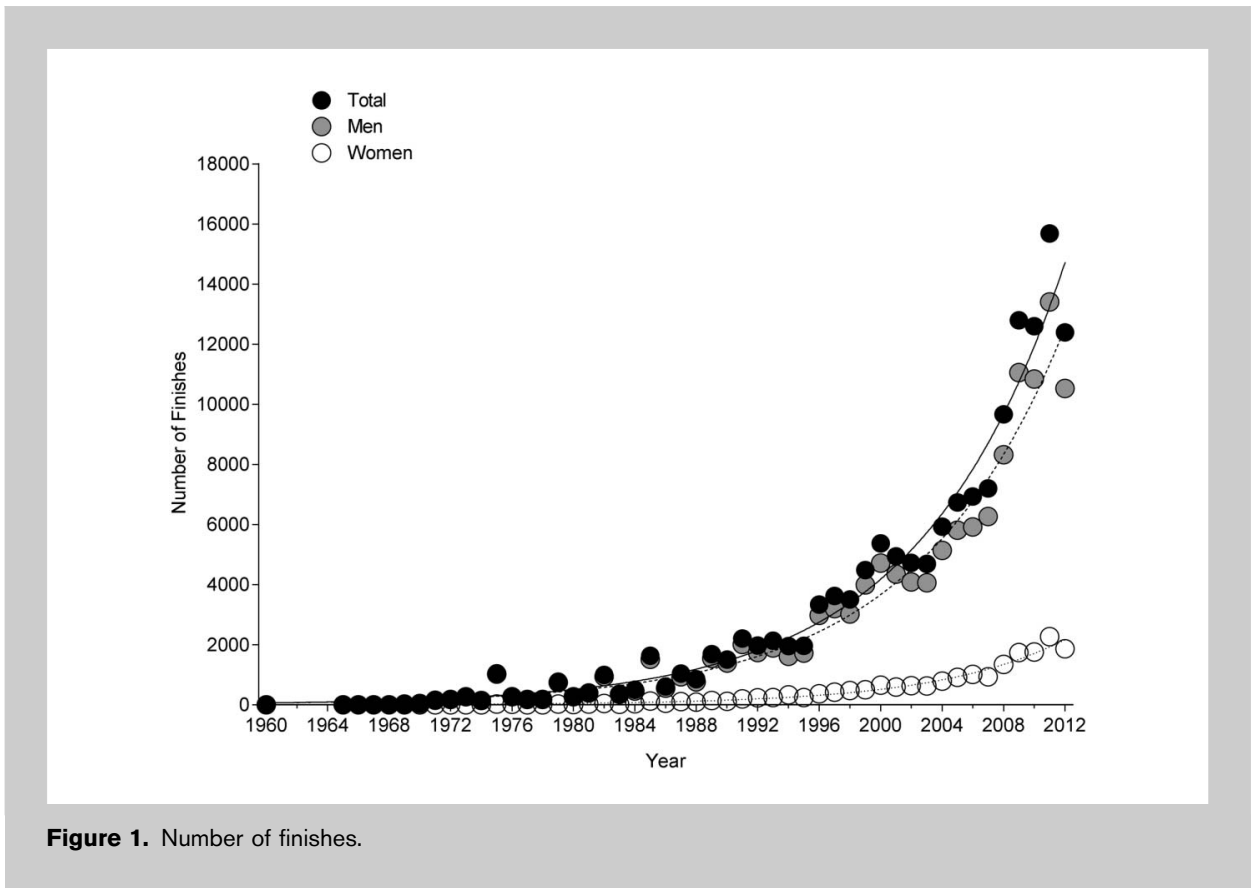

Over the past few years, it has been observed that the age of peak running performance in ultramarathoners increased for both women and men $(11,21,24,31)$. In 100 -miles ultramarathoners in the "Western States 100-Miles Endurance Run," the ages of the fastest runners have gradually risen to the extent that these runners were older than the ages at which the fastest marathons were run (24). In the " $100-\mathrm{km}$ Lauf Biel" in Switzerland, the fastest 10 women and men peaked at a similar age in ultramarathon running performance with $39.4 \pm 2.3$ years for men and $40.4 \pm 1.9$ years for women, respectively (31). The top performance in a $100-\mathrm{km}$ ultramarathon was 

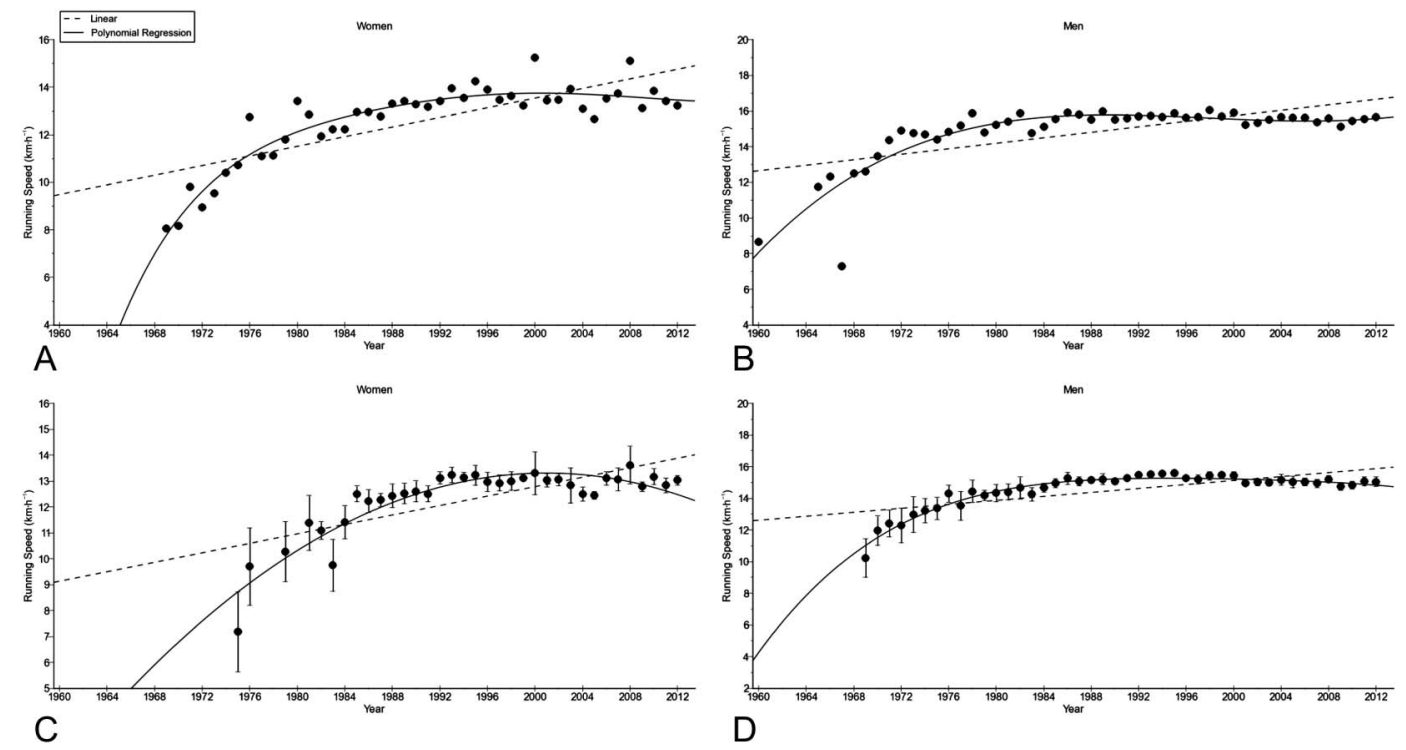

$\mathrm{D}$

Figure 2. Running speed of the annual fastest women (panel A) and men (panel B) and the annual 10 fastest women (panel C) and men (panel D).

attained at a higher age compared with a $42-\mathrm{km}$ marathon $(26,31)$. Thus, a large number of training years and extensive previous experience in endurance running is needed for a successful finish in an ultramarathon $(24,29,31)$. Similar findings for the increase in the age of peak ultra-endurance performance have been reported for Ironman triathletes. In the "Ironman Hawaii," the age of the annual top 10 women and men increased between 1983 and 2012, and the athletes were able to improve their performance (18). However, when worldwide trends in ultramarathon running were

TABLE 2. Multilevel regression analyses for change in running speed across years for the annual fastest and annual 10 fastest women and men (model 1) with correction for multiple finishes (model 2) and with correction for multiple finishes and age of athletes with multiple finishes (model 3).

\begin{tabular}{lcccccc}
\hline & Model & $\beta$ & $S E(\beta)$ & Stand. $\beta$ & $T$ & $p$ \\
\hline Annual fastest men & 1 & 0.077 & 0.014 & 0.640 & 5.705 & $<0.0001$ \\
& 2 & 0.077 & 0.014 & 0.640 & 5.705 & $<0.0001$ \\
Annual fastest women & 3 & 0.084 & 0.014 & 0.696 & 5.953 & $<0.0001$ \\
& 1 & 0.101 & 0.013 & 0.780 & 8.068 & $<0.0001$ \\
Annual 10 fastest men & 2 & 0.101 & 0.013 & 0.780 & 8.068 & $<0.0001$ \\
& 3 & 0.095 & 0.009 & 0.728 & 10.850 & $<0.0001$ \\
Annual 10 fastest women & 1 & 0.063 & 0.003 & 0.656 & 18.195 & $<0.0001$ \\
& 2 & 0.063 & 0.003 & 0.656 & 18.195 & $<0.0001$ \\
& 3 & 0.063 & 0.003 & 0.663 & 18.365 & $<0.0001$ \\
& 1 & 0.091 & 0.005 & 0.670 & 16.845 & $<0.0001$ \\
& 2 & 0.091 & 0.005 & 0.670 & 16.845 & $<0.0001$ \\
& 3 & 0.091 & 0.005 & 0.672 & 17.598 & $<0.0001$ \\
\hline
\end{tabular}

investigated, the age of peak ultramarathon performance remained unchanged. In 100-miles ultramarathoners, the mean ages of the annual 10 fastest runners were $39.2 \pm 6.2$ years for women and $37.2 \pm 6.1$ years for men between 1998 and 2011 although both women and men improved running performance (45).

Apart from age, sex has been distinguished as an important influencing factor of running performance $(5,26,27)$. For example, men have larger hearts, a higher cardiac output, and a greater muscular strength compared with women $(5,39)$. Sex differences in physiological and anthropometric characteristics may explain the better performance in men compared with women for endurance running $(5,27,39)$. Several studies investigated the sex differences in running performance and suggested that the sex gap would narrow with increasing length of the race distance $(1,51)$. Speechly et al. (51) reported that women who were matched with men on their performance at $42.2 \mathrm{~km}$ were able to outrun men in a 90 $\mathrm{km}$ race. In contrast, Sparling et al. (50) showed that the sex difference in distance running has not evolved in recent years. 

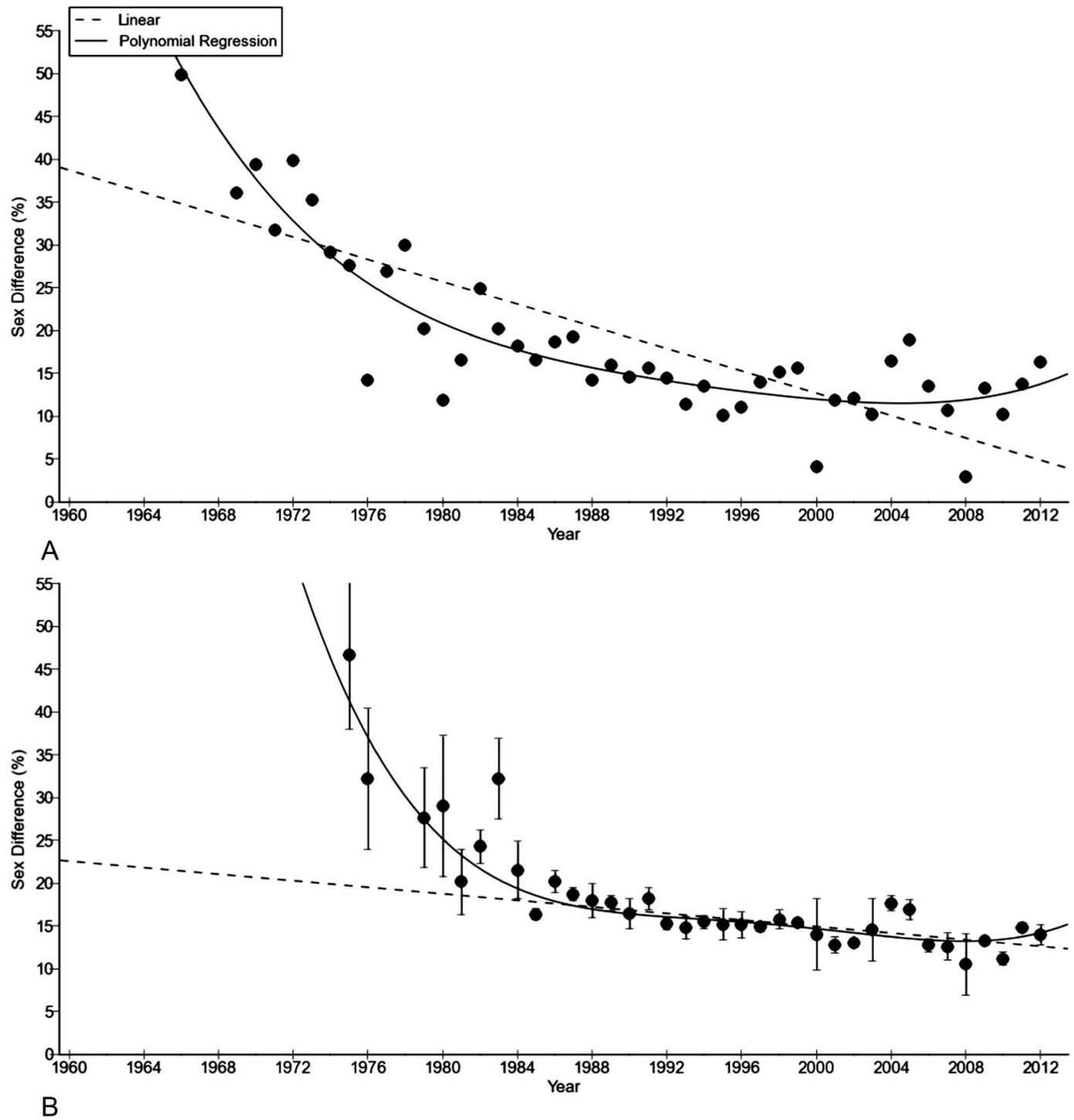

Figure 3. Sex difference in running speed for the annual fastest women and men (panel A) and the annual 10 fastest women and men (panel B).

Regarding the $100-\mathrm{km}$ ultramarathon distance, the average sex difference in performance was $\sim 22 \%$ for the annual top 10 runners in the "100-km Lauf Biel" over the 1998-2010 period (31). The race times for the top 10 women in the "100-km Lauf Biel" remained stable from 1998 to 2010, whereas race times of the top 10 men became slower across time (31). Similar findings were reported for the "Swiss Alpine Marathon" event, covering a distance of $78 \mathrm{~km}$ with a total change in altitude of approximately 2,260 m (11). However, the sex difference in performance was only $\sim 20 \%$ for the annual top 10 runners over the years (11). In contrast, in the study of Coast et al. (6) investigating athletes covering distances between $100 \mathrm{~m}$ and $200 \mathrm{~km}$, the sex difference accounted to $12.4 \%$.
Ultramarathon running is an outstanding model to analyze the age-related changes in running performance because the energetic loads and demands in an ultramarathon such as $100-\mathrm{km}$ ultramarathon are greater than in a traditional marathon of $42.2 \mathrm{~km}(26,31)$. Recent studies investigating "Ironman Hawaii” (18) and 100-miles ultramarathon (45) showed that ultra-endurance performance improved but the change in the age of peak ultraendurance performance was different. Although the age of peak performance in 100-mile runners remained unchanged across years (45), the age of the best Ironman triathletes in "Ironman Hawaii" increased over time (18).

Therefore, this study expands the existing data relating to age and sex in ultramarathon running by analyzing the age of 
TABLE 3. Multilevel regression analyses for the change in sex differences across years for the annual fastest and the annual 10 fastest runners (model 1) and with correction for multiple finishes (model 2).

\begin{tabular}{lcccccc}
\hline & Model & $\beta$ & $S E(\beta)$ & Stand. $\beta$ & $T$ & $p$ \\
\hline Annual fastest & 1 & -0.652 & 0.076 & -0.789 & -8.526 & $<0.0001$ \\
Annual 10 fastest & 2 & -0.652 & 0.076 & -0.789 & -8.526 & $<0.0001$ \\
& 1 & -0.526 & 0.027 & -0.714 & -19.295 & $<0.0001$ \\
& 2 & -0.526 & 0.027 & -0.714 & -19.295 & $<0.0001$ \\
\hline
\end{tabular}

peak ultra-running performance of all $100-\mathrm{km}$ ultramarathoners competing worldwide from 1960 to 2012. Within this framework, the aims of this study were to examine (a) the change in $100-\mathrm{km}$ running performance for both women and men from 1960 to 2012 and (b) the age of peak ultra-running performance in $100-\mathrm{km}$ ultramarathon during the same period. Regarding existing literature, we hypothesized (a) an improvement of

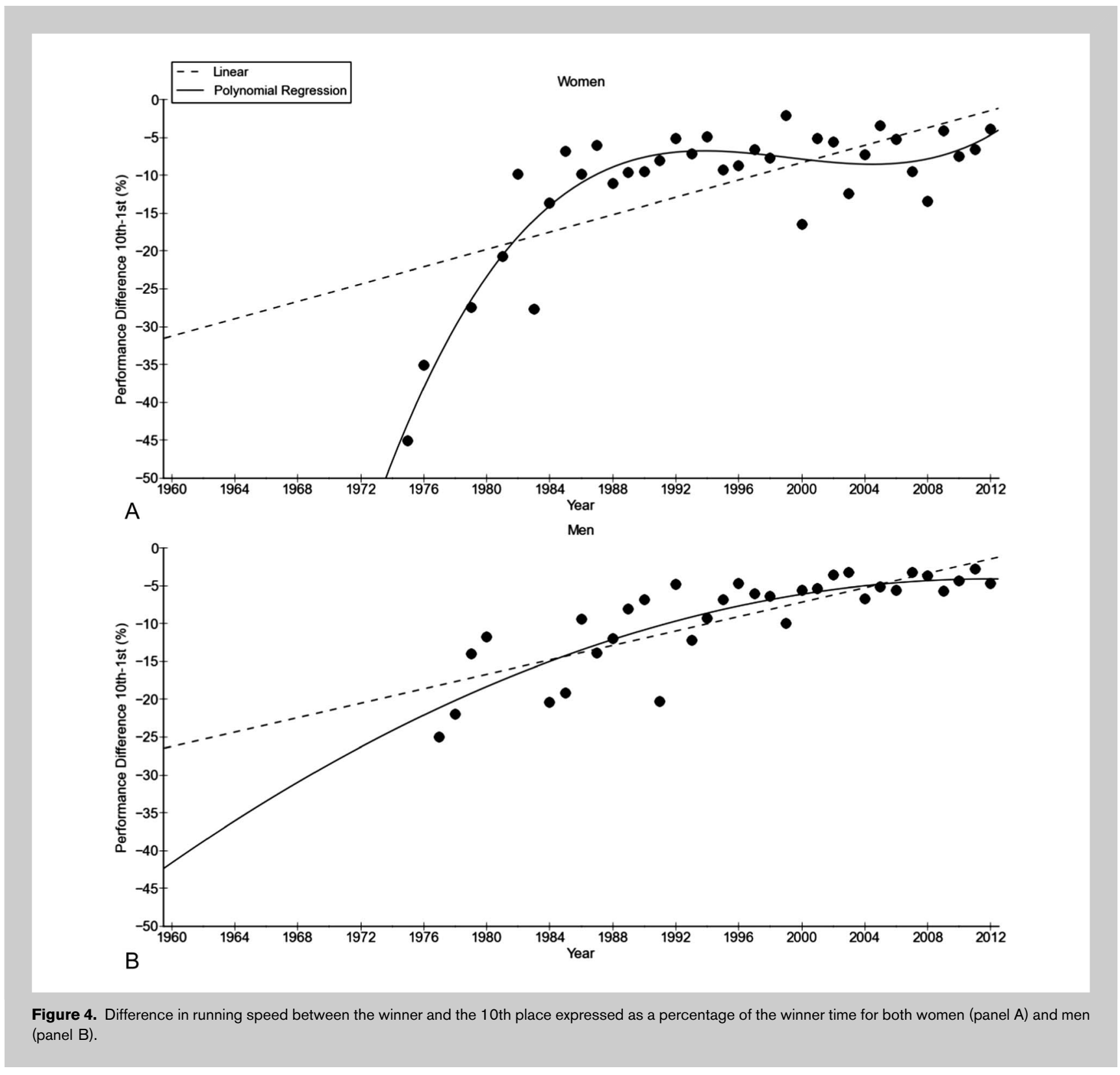




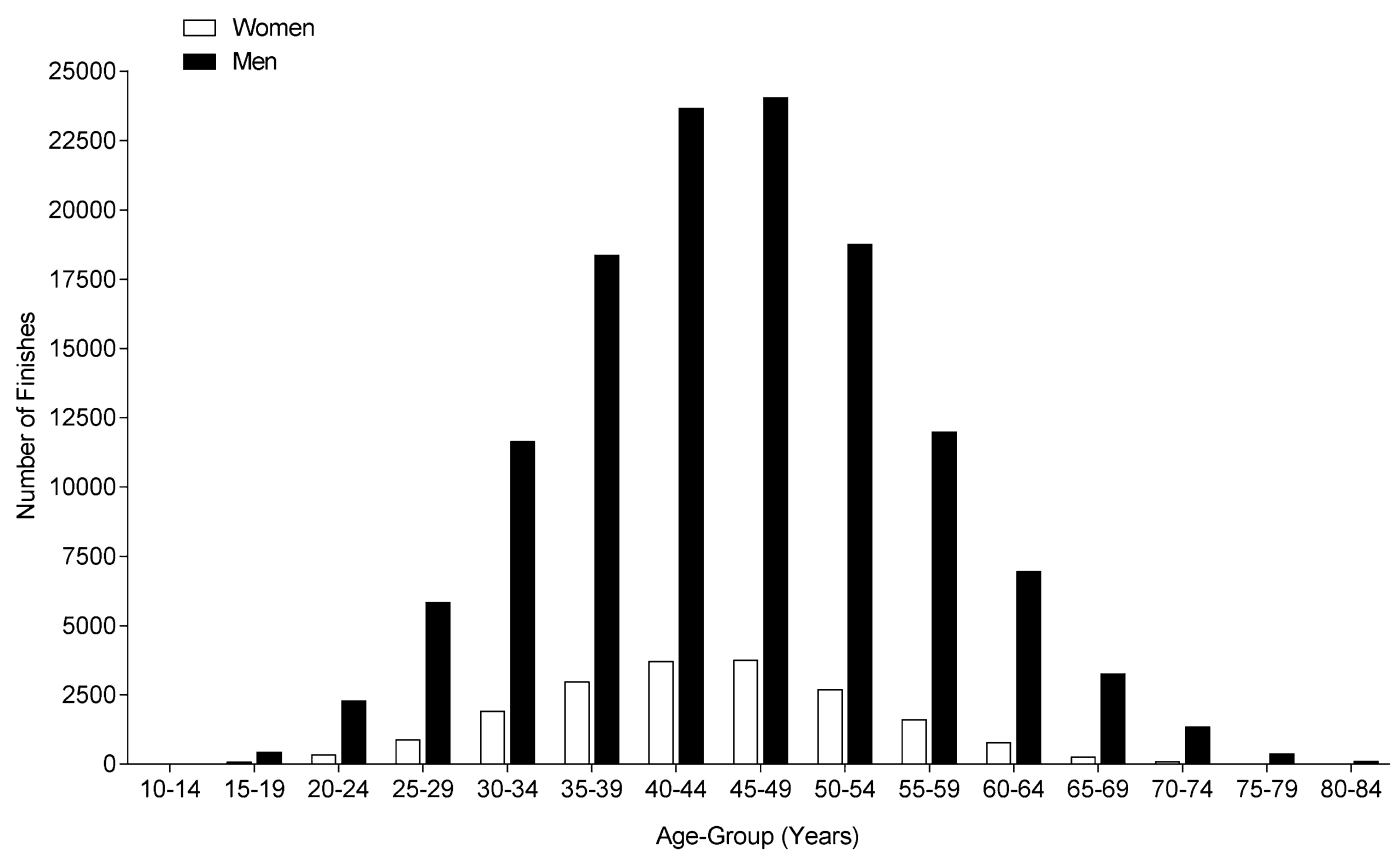

Figure 5. Distribution of the finishes in age groups for women and men.

running performance of $100-\mathrm{km}$ ultramarathoners and (b) that the age of peak ultra-running performance would increase during the studied period. The knowledge of the age of peak ultramarathon performance would help athletes and coaches to plan an ultramarathon career.

\section{Methods}

\section{Experimental Approach to the Problem}

To test our hypotheses, all women and men whoever finished worldwide in a $100-\mathrm{km}$ ultramarathon between 1960 and 2012 were analyzed regarding aspects of participation, performance, and age.

\section{Subjects}

Subjects between 18 and 84 years were all finishers of all $100-\mathrm{km}$ ultramarathons held worldwide between 1960 and 2012. The data set for this study was obtained from the race Web site www.ultra-marathon.org. This database records every result of any ultramarathon held worldwide. The study was approved by the Institutional Review Board of St. Gallen, Switzerland, with a waiver of the requirement for informed consent given that the study involved the analysis of publicly available data.

\section{Procedures}

To determine peak running performance and the age of peak running performance, race times of the annual top and of the annual top 10 women and men were determined and further analyzed. Performance was expressed as running speed $\left(\mathrm{km} \cdot \mathrm{h}^{-1}\right)$ using the equation (running speed $\left.\left[\mathrm{km} \cdot \mathrm{h}^{-1}\right]\right)=$ (race distance $[\mathrm{km}]) /($ race time $[\mathrm{h}]$ ). If less than the needed amount of athletes was available in a certain year, the respective year was excluded from data analysis. Additionally, the density in performance between the winner and the 10th place was determined if possible (i.e., at least 10 finishers in the respective year) using the equation (performance density between the first and 10th places) $=$ (performance of the 10th place - performance of the first place)/(performance of the first place) $\times 100$, and thus expressed as percentage of the winners performance.

\section{Statistical Analyses}

To increase the reliability of the data analyses, each set of data was tested for normal distribution and for homogeneity of variances before statistical analyses. Normal distribution was tested using a D'Agostino and Pearson omnibus normality test, and homogeneity of variances was tested using a Levene's test. Trends in performance were analyzed using regression analysis with "straight line" and "exponential growth equation" model, whereas for each set of data (e.g., each sex) both models where compared using Akaike's information criteria (AIC) to decide which model shows the highest probability of correctness. Single- and multilevel regression analyses were used to investigate changes in performance and age of the finishers across years. A hierarchical regression model was used to avoid the impact of a cluster effect on results in case one athlete finished more than once in the annual top or annual top 10 for the analysis of the 


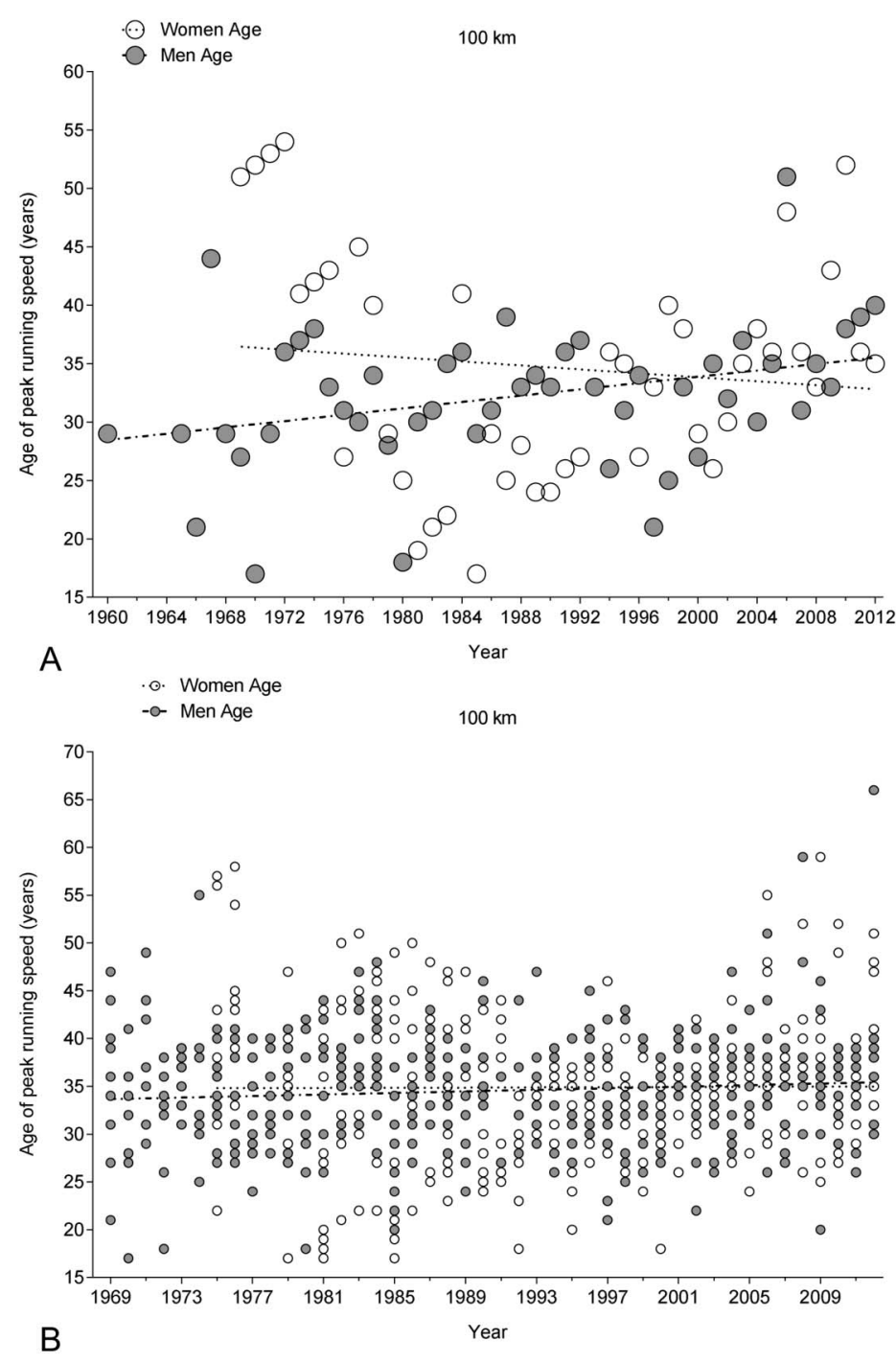

Figure 6. Age of the annual fastest women and men (panel A) and the annual 10 fastest women and men (panel B).

USA), CurveExpert Professional (version 2.0.3; Hyams D.G., Huntsville, AL, USA), and GraphPad Prism (version 6.01; GraphPad Software, La Jolla, CA, USA). Significance was accepted at $p \leq 0.05$ (2-sided for $t$-tests). Data in the text and figures are given as mean $\pm S D$.

\section{Results}

\section{Participation Trends}

Complete data with age and race time were available for 148,017 finishers with 18,998 women and 129,019 men. For both women and men, the number of finishes increased exponentially across years (Figure 1). The percentage of female finishes increased from 3.8\% in 1969 to $15.0 \%$ in 2012 with an average female participation of $12.8 \pm 5.3 \%$ across all years.

\section{Performance Trends}

Running speed of the annual fastest women increased from $8.06 \mathrm{~km} \cdot \mathrm{h}^{-1}$ in 1969 to 13.22 $\mathrm{km} \cdot \mathrm{h}^{-1}$ in 2012 (polynomial regression sixth degree, $r^{2}=$ $0.87, S E=0.63$; Figure $2 \mathrm{~A}$ ) and in the annual fastest men from $8.67 \mathrm{~km} \cdot \mathrm{h}^{-1}$ in 1960 to $15.65 \mathrm{~km} \cdot \mathrm{h}^{-1}$ in 2012 (polynomial regression fourth degree, $r^{2}=0.79, S E=0.81$; Figure 2B) also when controlled for multiple finishes (Table 2). For

annual top and annual top 10 athletes regarding the analysis of the overall performance and the age of peak performance. Furthermore, regression analyses of performance were corrected for age of athletes to prevent misinterpretation of an "age effect" as a "time effect." Because the change in sex difference in endurance is assumed to be nonlinear (44), we additionally calculated for running speed, sex difference, and performance density using the non-linear regression model to compare with the linear model to find the best model. Because the best-fit model was in all cases a polynomial regression, we compared the best-fit models to the linear models using AIC and $F$-test to show which model would be the most appropriate to explain the trend of the data (Table 1). Statistical analyses were performed using IBM SPSS Statistics (version 21; IBM SPSS, Chicago, IL, the annual 10 fastest women, running speed increased from $7.18 \pm 1.54 \mathrm{~km} \cdot \mathrm{h}^{-1}$ in 1975 to $13.03 \pm 0.18 \mathrm{~km} \cdot \mathrm{h}^{-1}$ in 2012 (polynomial regression second degree, $r^{2}=0.84, S E=0.54$; Figure 2C) and for the annual 10 fastest men from $10.23 \pm$ $1.22 \mathrm{~km} \cdot \mathrm{h}^{-1}$ in 1969 to $15.05 \pm 0.29 \mathrm{~km} \cdot \mathrm{h}^{-1}$ in 2012 (polynomial regression fourth degree, $r^{2}=0.94, S E=0.28$, Figure 2D) also when controlled for multiple finishes (Table 2). The sex difference in running speed decreased from $56.1 \%$ in 1965 to $16.3 \%$ in 2012 for the annual fastest finishers (polynomial regression fourth degree, $r^{2}=0.87, S E=4.21$; Figure $3 \mathrm{~A}$ ) and from $46.7 \pm 8.7 \%$ in 1975 to $14.0 \pm 1.2 \%$ in 2012 for the annual 10 fastest finishers (polynomial regression fifth degree, $r^{2}=0.86, S E=0.92$; Figure $3 \mathrm{~B}$ ) also when controlled for multiple finishes (Table 3 ). The density in performance from the 10th to the fastest competitor 
TABLE 4. Multilevel regression analyses for change in age across years for the annual fastest and annual 10 fastest women and men (model 1) and with correction for multiple finishes (model 2).

\begin{tabular}{lcccrrr}
\hline & Model & $\beta$ & $S E(\beta)$ & Stand. $\beta$ & $T$ & $p$ \\
\hline Annual fastest men & 1 & 0.136 & 0.058 & 0.321 & 2.321 & 0.025 \\
& 2 & 0.136 & 0.058 & 0.321 & 2.321 & 0.025 \\
Annual fastest women & 1 & -0.085 & 0.116 & -0.112 & -0.731 & 0.469 \\
& 2 & -0.085 & 0.116 & -0.112 & -0.731 & 0.469 \\
Annual 10 fastest men & 1 & 0.041 & 0.022 & 0.088 & 1.856 & 0.064 \\
Annual 10 fastest women & 2 & 0.041 & 0.022 & 0.088 & 1.856 & 0.064 \\
& 1 & 0.005 & 0.039 & 0.007 & 0.124 & 0.902 \\
& 2 & 0.005 & 0.039 & 0.007 & 0.124 & 0.902 \\
\hline
\end{tabular}

tially through a combination of an increase in the participation of runners older than 40 years and a growth in the participation of women (23). Also for $100-\mathrm{km}$ ultramarathoners, Knechtle et al. (31) reported that the number of master athletes from the age groups 40-49 years and 50-59 years for both women and men increased from 1998 to 2010 in the "100-km Lauf Biel" in Switzerland. The number of master athletes is expected to increase, as the population in both developed and develop-

increased in women from $-45.1 \%(1986)$ to $-3.9 \%$ (2012) (polynomial regression third degree, $r^{2}=0.82, S E=4.07$; Figure 4A) and in men from $-28.6 \%$ (1969) to $-5.4 \%$ (2012) (polynomial regression second degree, $r^{2}=0.69, S E=3.48$; Figure 4B).

\section{Age Trends}

Most of the finishers were classified in the age group 45-49 years for both women and men (Figure 5). The age of the annual fastest men increased from 29 years in 1960 to 40 years in 2012 (Figure 6A) also when controlled for multiple finishes (Table 4). The age of the annual fastest women remained unchanged at $35.0 \pm 9.7$ years between 1969 and 2012, also when controlled for multiple finishes (Table 4). For the annual 10 fastest women and men, the age of the fastest competitors remained unchanged at $34.9 \pm 3.2$ and $34.5 \pm 2.5$ years, respectively (Figure $6 \mathrm{~B}$ ), also when controlled for multiple finishes (Table 4).

\section{Discussion}

The aims of this study were to (a) examine the change in $100-\mathrm{km}$ ultra-running performance for both women and men from 1960 to 2012 and (b) determine the age of peak ultra-running performance in $100-\mathrm{km}$ ultramarathon during the same period. The main findings were (a) an exponential increase in number of both female and male finishers with $\sim 13 \%$ of female participation, (b) the running speed of the annual fastest women and men improved over time, and (c) the age of the fastest runners remained unchanged across years at $\sim 35$ years for both women and men.

The number of both female and male $100-\mathrm{km}$ ultrarunners finishers increased across years. Similarly, Rüst et al. (45) reported an exponential increase in the number of 100 miles ultramarathoners. Apart from ultra-running, also other ultra-endurance disciplines such as ultra-swimming $(10,16)$ enjoyed an increase in participation in the past decades.

In 100-miles races held in the USA, the annual number of races and the annual number of finishes increased exponen- ing countries are aging caused by the substantial gain in longevity and a decreasing fertility worldwide $(41,52)$.

Women represented on average for $\sim 13 \%$ of the total field of ultra-runners with an increase from $3.8 \%$ in 1969 to $15.0 \%$ in 2012. Similar findings were reported in other studies such as in the 78-km "Swiss Alpine Marathon," where women's participation increased from $\sim 10 \%$ in 1998 to $16 \%$ in 2011 (11). In 100-miles ultramarathons, the percentage of female finishers increased from 16.7 to $19.1 \%$ between 1998 and 2011 (45). Hoffman et al. (21) reported a sex difference in participation of $\sim 20 \%$ for $161-\mathrm{km}$ ultramarathoners. The different results might be explained by the different lengths of the races and the different time periods. Additionally, motivation might act as a fundamental reason for the low women participation rate and to the great attendance of men $(8,9,19,34)$. For female ultra-runners, the main drivers for involvement were noncompetitive factors such as general health orientation and psychological coping (34). Women's incentives to exercise are to improve their fitness level and physical health, to gain affiliation and to control their body weight (19). Women ultra-runners seem to be task oriented, motivated by personal achievement and health conscious individuals (34). In contrary, men have a predisposition for long-lasting competitiveness and thus motivated to train with a high volume $(8,9)$.

In accordance with our hypothesis to find an improvement of running performance of $100-\mathrm{km}$ ultramarathoners, performance in both female and male $100-\mathrm{km}$ ultramarathoners improved across years. Similar findings with an improvement in performance have been reported for 100-miles ultramarathoners competing in the "The Western States 100-Mile Endurance Run" (24) and in the worldwide analysis for 100 -miles ultramarathons (45). Also in other ultramarathons such as "Badwater," running performance improved in both women and men (7). However, in the "Spartathlon," both women and men were not able to improve race times in recent years (7). Most probably athletes in the longest and toughest 
ultramarathons held worldwide have now reached their performance limit.

The sex difference in running speed decreased across years for both the annual fastest and the annual 10 fastest finishers. In 2012, the sex difference was $16.3 \%$ for the annual fastest and $14.0 \%$ for the annual 10 fastest finishers. These values were slightly lower compared with previous studies where the average sex difference accounted to $17-20 \%$ for the fastest finishers and $20-22 \%$ for the top 10 runners $(11,21,31)$. Interestingly, the sex difference in ultramarathon performance showed no change for 100-miles ultramarathoners competing between 1998 and 2011 (45). The sex difference in performance remained unchanged at $15.0 \pm 8.3 \%$ for the annual fastest and at $17.0 \pm 4.1 \%$ for the annual 10 fastest finishers (45). Most probably, the longer distance in 100 miles $(161 \mathrm{~km})$ compared with $100 \mathrm{~km}$ might explain this difference.

In the study of Coast et al. (6) relating to running distances between $100 \mathrm{~m}$ and $200 \mathrm{~km}$, the sex difference accounted to $12.4 \%$. The existing sex gaps in running performance can partly be attributed to physiological sex differences such as the lower skeletal muscle mass and the lower cardiac output in women compared with men $(5,39)$. Hunter et al. (25) showed that the physiological sex difference in marathon running velocity was not the only cause of the sex difference. The non-physiological difference could be attributed to the lower number of women finishers relative to men because of a sampling bias (25). Therefore, the lower participation rates of women compared with men can have a large influence on the sex difference in running, and the sampling bias may mask the physiological limits of women (25). Lombardo (38) argued that sport began as a method for men to evolve the abilities needed in primitive hunting and warfare. Hence, sports reveal the skills required for success at fighting and primitive hunting, which could be an advantage for men finishers (38). Other explanations for men's dominance in distance running could be the greater training motivations in men $(8,9)$. To succeed in distance running, enduring competitiveness is an important factor $(8,9)$. Deaner (8) hypothesized that men were substantially more competitive than women and therefore more motivated to engage in highvolume training.

The average time difference between the winner and the 10th placed athlete decreased in both men and women. In 2012, this time difference was smaller for women than for men. The density for the top 10 finishers was higher for women than for men. The density for the top 10 men and the top 10 women was approximately the same in 2012 .

It has been postulated that women may outperform men with increasing race distance $(1,6)$. It has been previously observed that female ultramarathoners were more resistant to fatigue than comparable male ultramarathoners (1). The present findings display that the sex gap in $100-\mathrm{km}$ ultramarathon running became reduced since 1960. However, Sparling et al. (50) reported that the sex difference in distance running performance has not changed between 1980 and 1996. Although the sex difference decreased across years, it seems unlikely that women will be faster than men in the near future in $100-\mathrm{km}$ ultramarathon distance.

We hypothesized that the age of peak ultra-running performance would increase during the studied period. However, the annual top 10 women and men were of the same age of $\sim 35$ years between 1969 and 2013. Although other studies showed that the age of peak ultra-endurance performance increased across years $(18,24)$, analyses of Olympic track and field and swimming data between 1896 and 1980 showed that the age at which peak performance was achieved remained remarkably consistent (48).

The age of peak ultramarathon performance might increase with increasing length or duration of a race. In 100 -miles ultramarathoners, the age of the annual fastest women was $39.0 \pm 5.5$ years for women and $37.0 \pm 6.0$ years for men with no change across years (45). Similarly, the age of the annual 10 fastest finishers was $39.2 \pm 6.2$ years for women and $37.2 \pm 6.1$ years for men with no change across years (45). In 24-hour ultramarathoners, the best runners were even older than 40 years (53). The age of the annual top 10 women decreased from $42.6 \pm 5.9$ years to $40.1 \pm 7.0$ years. For the annual top 10 men, the age of peak running speed remained unchanged at $42 \pm 2$ years. Future studies need to investigate the age of peak performance in longer races such as continental crossing like "Run across America" or "Trans Europe Foot Race."

The present findings confirm the results of Tanaka (52) regarding running distances up to $42 \mathrm{~km}$, that peak endurance performance in running is sustained until $\sim 35$ years of age. An accumulation of training years and of experience in such ultra-endurance races is essential for a success finish in endurance running until the velocity is outbalanced by human aging $(14,24,29,31)$. The aging process in humans is described by a functional degeneration in the major biological system (42) including the cardiovascular (4), metabolic (40), respiratory (48), and musculoskeletal (15) systems. Also, the atrophy of skeletal muscles is not perceivable for most people until the age of 40 years (15). Accordingly to Faulkner et al. (15), a significant atrophy of the skeletal muscles occurs mainly beyond the age of 50 years. According to Tanaka (52), the physiological determinants such as maximum oxygen consumption $\left(\mathrm{V}_{2}\right.$ max $)$ and lactate threshold are mainly responsible for decline in performance with increasing age. Regarding combinations of physiological factors (52), skeletal muscle (15), and number of training years (29), 100-km ultramarathoners seemed to achieve their best performances in their mid-30s.

The age classification system differs from sport to sport in accordance to the age at which the world record peaks (43). Master athletes are defined as runners over the age of 35 years who are keen and competitive athletes (43). According to the current age-based category in running, the world best $100-\mathrm{km}$ ultramarathon runners are close to master athletes, by definition. 
The strength of this study is the large sample size and the inclusion of multivariate and nonlinear regression analyses. However, although the database seems highly reliable, some smaller races might not be included leading to a selection bias. Regarding the study design, a limitation in this crosssectional study is the fact that we were unable to take into consideration factors of endurance performance such as physiological $(35,40,46)$ and anthropometric parameters $(28,29)$, training $(29,32)$, previous experience $(28,30)$, fluid and food intake $(2,3)$, motivation $(20,34)$, medical problems $(33,47)$, and environmental conditions of the race $(12,13)$. Nevertheless, this study reveals beneficial information, because it expands the existing data of age and gender influence in ultramarathon running.

\section{Practical Applications}

The number of female and male finishers increased exponentially in $100-\mathrm{km}$ ultramarathon races held worldwide between 1960 and 2012. Running speed increased for the annual fastest and annual 10 fastest women and men. The sex difference decreased to $16.3 \%$ for the annual fastest and to $14.0 \pm 1.2 \%$ for the annual 10 fastest finishers. The age of the annual 10 fastest finishers was at $\sim 35$ years for both women and men. To conclude, $100-\mathrm{km}$ ultramarathoners became faster, the sex difference in performance decreased, but the age of the fastest finishers remained unchanged at $\sim 35$ years. For athletes and coaches, $100-\mathrm{km}$ ultramarathoners improved performance between 1960 and 2012; however, the age of the fastest athletes remained unchanged at 35 years over time. To plan a career as a $100-\mathrm{km}$ ultramarathoner, the fastest $100-\mathrm{km}$ race times will be achieved at the age of $\sim 35$ years for both women and men.

\section{ReFERENCES}

1. Bam, J, Noakes, TD, Juritz, J, and Dennis, SC. Could women outrun men in ultramarathon races? Med Sci Sports Exerc 29: 244-247, 1997.

2. Bürge, J, Knechtle, B, Knechtle, P, Gnädinger, M, Rüst, CA, and Rosemann, T. Maintained serum sodium in male ultra-marathonersthe role of fluid intake, vasopressin, and aldosterone in fluid and electrolyte regulation. Horm Metab Res 43: 646-652, 2011.

3. Cejka, C, Knechtle, B, Knechtle, P, Rüst, CA, and Rosemann, T. An increased fluid intake leads to feet swelling in 100-km ultramarathoners-an observational field study. J Int Soc Sports Nutr 9: 11, 2012.

4. Cheitlin, M. Cardiovascular physiology-changes with aging. Am J Geriatr Cardiol 12: 9-13, 2003.

5. Cheuvront, S, Carter, R, Deruisseau, K, and Moffatt, R. Running performance differences between men and women: An update. Sports Med 35: 1017-1024, 2005.

6. Coast, JR, Blevins, J, and Wilson, B. Do gender differences in running performance disappear with distance? Can J Appl Physiol 29: 139-145, 2004.

7. Da Fonseca-Engelhardt, K, Knechtle, B, Rüst, CA, Knechtle, P, Lepers, R, and Rosemann, T. Participation and performance trends in ultra-endurance running races under extreme conditions-“Spartathlon" versus "Badwater". Extrem Physiol Med 2: 15, 2013.

8. Deaner, RO. Distance running as an ideal domain for showing a sex difference in competitiveness. Arch Sex Behav 42: 413-428, 2013.
9. Deaner, RO and Mitchell, D. More men run relatively fast in U.S. road races, 1981-2006: A stable sex difference in non-elite runners. Evol Psychol 9: 600-621, 2011.

10. Eichenberger, E, Knechtle, B, Knechtle, P, Rüst, CA, Rosemann, T, and Lepers, R. Best performances by men and women open-water swimmers during the "English Channel Swim" from 1900 to 2010. J Sports Sci 30: 1295-1301, 2012.

11. Eichenberger, E, Knechtle, B, Rüst, CA, Rosemann, T, and Lepers, R. Age and sex interactions in mountain ultramarathon running-the Swiss Alpine Marathon. Open Access J Sports Med 3: 73-80, 2012.

12. El Helou, N, Tafflet, M, Berthelot, G, Tolaini, J, Marc, A, Guillaume, M, Hausswirth, C, and Toussaint, JF. Impact of environmental parameters on marathon running performance. PLoS One 7: e37407, 2012.

13. Ely, M, Cheuvront, S, Roberts, W, and Montain, S. Impact of weather on marathon-running performance. Med Sci Sports Exerc 39: 487-493, 2007.

14. Faulkner, J, Davis, C, Mendias, C, and Brooks, S. The aging of elite male athletes: Age-related changes in performance and skeletal muscle structure and function. Clin J Sport Med 18: 501-507, 2008.

15. Faulkner, J, Larkin, L, Claflin, D, and Brooks, S. Age-related changes in the structure and function of skeletal muscles. Clin Exp Pharmacol Physiol 34: 1091-1096, 2007.

16. Fischer, G, Knechtle, B, Rüst, CA, and Rosemann, T. Male swimmers cross the English Channel faster than female swimmers. Scand J Med Sci Sports 23: e48-e55, 2013.

17. Frederick, $\mathrm{C}$ and Ryan, R. Differences in motivation for sport and exercise and their relations with participation and mental health. J Sport Behav 16: 124-146, 1993.

18. Gallmann, D, Knechtle, B, Rüst, CA, Rosemann, T, and Lepers, R. Elite triathletes in "Ironman Hawaii" get older but faster. Age (Dordr) 36: 407-416, 2014.

19. Gill, $\mathrm{K}$ and Overdorf, V. Incentives for exercise in younger and older women. J Sport Behav 17: 87-97, 1994.

20. Hodge, K, Allen, JB, and Smellie, L. Motivation in master sport: Achievement and social goals. Psychol Sport Exerc 9: 157-176, 2008.

21. Hoffman, MD. Performance trends in 161-km ultramarathons. Int J Sports Med 31: 31-37, 2010.

22. Hoffman, MD and Fogard, K. Demographic characteristics of 161km ultramarathon runners. Res Sports Med 20: 59-69, 2012.

23. Hoffman, MD, Ong, JC, and Wang, G. Historical analysis of participation in $161 \mathrm{~km}$ ultramarathons in North America. Int J Hist Sport 27: 1877-1891, 2010.

24. Hoffman, MD and Wegelin, JA. The western states 100-Mile endurance run: Participation and performance trends. Med Sci Sports Exerc 41: 2191-2198, 2009.

25. Hunter, SK and Stevens, AA. Sex differences in marathon running with advanced age: Physiology or participation? Med Sci Sports Exerc 45: 148-156, 2013.

26. Hunter, SK, Stevens, AA, Magennis, K, Skelton, KW, and Fauth, M. Is there a sex difference in the age of elite marathon runners? $\mathrm{Med} \mathrm{Sci}$ Sports Exerc 43: 656-664, 2011.

27. Joyner, MJ. Physiological limiting factors and distance running: Influence of gender and age on record performances. Exerc Sport Sci Rev 21: 103-133, 1993.

28. Knechtle, B, Knechtle, $\mathrm{P}$, and Rosemann, T. Race performance in male mountain ultra-marathoners: Anthropometry or training? Percept Mot Skills 110: 721-735, 2010.

29. Knechtle, B, Knechtle, P, Rosemann, T, and Lepers, R. Predictor variables for a $100-\mathrm{km}$ race time in male ultra-marathoners. Percept Mot Skills 111: 681-693, 2010. 
30. Knechtle, B, Knechtle, P, Rosemann, T, and Senn, O. What is associated with race performance in male $100-\mathrm{km}$ ultra-marathonersanthropometry, training or marathon best time? J Sports Sci 29: 571-577, 2011.

31. Knechtle, B, Rüst, CA, Rosemann, T, and Lepers, R. Age-related changes in 100-km ultra-marathon running performance. Age (Dordr) 34: 1033-1045, 2012.

32. Knechtle, B, Wirth, A, Knechtle, $\mathrm{P}$, and Rosemann, T. Training volume and personal best time in marathon, not anthropometric parameters, are associated with performance in male $100-\mathrm{km}$ ultrarunners. J Strength Cond Res 24: 604-609, 2010.

33. Krabak, B, Waite, B, and Schiff, M. Study of injury and illness rates in multiday ultramarathon runners. Med Sci Sports Exerc 43: 23142320, 2011.

34. Krouse, RZ, Ransdell, LB, Lucas, SM, and Pritchard, ME. Motivation, goal orientation, coaching, and training habits of women ultrarunners. J Strength Cond Res 25: 2835-2842, 2011.

35. Landman, Z, Landman, G, and Fatehi, P. Physiologic alterations and predictors of performance in a $160-\mathrm{km}$ ultramarathon. Clin J Sport Med 22: 146-151, 2012.

36. Lepers, $\mathrm{R}$ and Cattagni, $\mathrm{T}$. Do older athletes reach limits in their performance during marathon running? Age (Dordr) 34: 773-781, 2012

37. Leyk, D, Rüther, T, Wunderlich, M, Sievert, A, Essfeld, D, Witzki, A Erley, O, Küchmeister, G, Piekarski, C, and Löllgen, H. Physical performance in middle age and old age: Good news for our sedentary and aging society. Dtsch Arztebl Int 107: 809-816, 2010.

38. Lombardo, MP. On the evolution of sport. Evol Psychol 10: 1-28, 2012.

39. Lynch, S and Hoch, A. The female runner: Gender specifics. Clin Sports Med 29: 477-498, 2010.

40. Murray, LA, Reilly, JJ, Choudhry, M, and Durnin, JV. A longitudinal study of changes in body composition and basal metabolism in physically active elderly men. Eur J Appl Physiol Occup Physiol 72: 215-218, 1996.

41. Northridge, ME. The strengths of an aging society. Am J Public Health 102: 1432, 2012.
42. Rae, D, Bosch, A, Collins, M, and Lambert, M. The interaction of aging and 10 years of racing on ultraendurance running performance. J Aging Phys Act 13: 210-222, 2005.

43. Reaburn, R and Dascombe, B. Endurance performance in master athletes. Eur Rev Aging Phys Act 5: 31-42, 2008.

44. Reinboud, W. Linear models can't keep up with sport gender gap. Nature 432: 147, 2004.

45. Rüst, CA, Knechtle, B, Rosemann, T, and Lepers, R. Analysis of performance and age of the fastest 100-mile ultra-marathoners worldwide. Clinics (Sao Paulo) 68: 605-611, 2013.

46. Saunders, P, Pyne, D, Telford, R, and Hawley, J. Factors affecting running economy in trained distance runners. Sports Med 34: 465485, 2004.

47. Scheer, BV and Murray, A. Al Andalus Ultra Trail: An observation of medical interventions during a 219-km, 5-day ultramarathon stage race. Clin J Sport Med 21: 444-446, 2011.

48. Schulz, R and Curnow, C. Peak performance and age among superathletes: Track and field, swimming, baseball, tennis, and golf. J Gerontol 43: P113-P120, 1988.

49. Sharma, G and Goodwin, J. Effect of aging on respiratory system physiology and immunology. Clin Interv Aging 1: 253-260, 2006.

50. Sparling, PB, O'Donnell, EM, and Snow, TK. The gender difference in distance running performance has plateaued: An analysis of world rankings from 1980 to 1996. rankings from 1980 to 1996. Med Sci Sports Exerc 30: 1725-1729, 1998.

51. Speechly, DP, Taylor, SR, and Rogers, GG. Differences in ultraendurance exercise in performance-matched male and female runners. Med Sci Sports Exerc 28: 359-365, 1996.

52. Tanaka, H. Endurance exercise performance in masters athletes: Age-associated changes and underlying physiological mechanisms. J Physiol 586: 55-63, 2008.

53. Zingg, M, Rüst, CA, Lepers, R, Rosemann, T, and Knechtle, B. Master runners dominate 24-h ultramarathons worldwidea retrospective data analysis from 1998 to 2011. Extrem Physiol Med 2: 21, 2013. 